\title{
Pengasuhan Anak Usia Dini Menurut Perspektif Ajaran Islam
}

\section{Cucu Sopiah}

Universitas muhammadiyah Cirebon

sofirindu@gmail.com

\begin{tabular}{l} 
Info Artikel \\
\hline Sejarah Artikel: \\
Diterima (Desember) (2018) \\
Disetujui (Januari) (2019) \\
Dipublikasikan (Januari) \\
(2019) \\
\hline Keywords: \\
Pengasuhan, Anak Usia \\
Dini, Persfektif Ajaran \\
Islam \\
\hline
\end{tabular}

\begin{abstract}
Abstrak
Akhlak perilakuyang diperlihatkan anak dapat tercermin dari siapa yang sudah mengasuhnya.Pengasuhan anak diperoleh dari orang yang terdekatnya baik di lingkungan rumah maupun dilingkungan sekolah. Guru merupakan lingkungan kedua yang terdekat setelah orang tua dirumah dapat ikut andil dalam pembentukan perilaku anak. Penelitian ini dilakukan di Taman-kanak Aisyiyah 48 pulo Asem Jakarta dimana didalam kegiatan belajar mengajarnya terdapat muatan penanaman ajaran persfektif Islam.Penelitian ini menggunakan penelitian kualitatif, data yang dikumpulkan dianalisis berdasarkan data kualitatif. Penelitian ini bertujuan untuk memberikan informasi bagaimana pengasuhan anak usia dini di TK Aisyiyah 48 menurut persfektif ajaran Islam. Hasil penelitian menunjukan bahwa pengasuhan anak usia dini menurut persfektif ajaran islam di TK Aisyiyah 48 melalui pengasuhan Keteladanan/Contoh Rasullah SAW, kelembutan, kasih sayang, bersikap adil dan kejujuran.
\end{abstract}

\begin{abstract}
The character of the behavior exhibited by the child can be reflected from who has taken care of him. Child care is obtained from those closest to him both at home and in the school environment. The teacher is the second closest environment after parents at home can contribute to the formation of children's behavior. This research was conducted in kindergarten Aisyiyah 48 pulo Asem Jakarta where in teaching and learning activities there is a content of the planting of Islamic perspective teachings. This research uses qualitative research, the data collected are analyzed based on qualitative data. This study aims to provide information on how to care for young children in kindergarten Aisyiyah 48 according to the perspective of Islamic teachings. The results showed that early childhood care according to the perspective of Islamic teachings in Kindergarten Aisyiyah 48 through parenting / Examples of Rasullah SAW, tenderness, compassion, being fair and honesty.
\end{abstract}

(C) 2019 Cucu Sopiah Under the license CC BY-SA 4.0

\section{Pendahuluan}

Zaman modern saat ini banyak orang tua yang semakin resah dengan tingkah laku anak-anaknya dalam pergaulan, hal tersebut disebabkan oleh beberapa faktor yang ikut serta membentuk perilaku anak sejak dini baik dari pengasuhan orang tua dan dari 
lingkungan. Pendidikan anak usia dini merupakan pendidikan mendasar untuk membentuk individu yang berkualitas dimasa mendatang. Upaya pendidikan anak usia dini tidak akan lepas dari system pendidikan yang diterapkan.

Sistem pendidikan Islam sebagai sebuah system yang memiliki tujuan-tujuan untuk membentuk generasi masa depan yang berkualitas dapat dijadikan acuan untuk membentuk pribadi anak agar dapat memiliki pribadi yang memiliki akhlakul karimah yang baik, salah satunya adalah melalui pengasuhan anak usia dini menurut persfektif Islam.

Banyaknya system pendidikan disekolah menawarkan beberapa visi,misi dan tujuan yang akan membawa anak kemana akan diarahkan, membuat para orang tua khawatir dengan menitipkan anaknya disekolah dengan beberapa alasan dan pertimbangan. Banyak sekolahan yang bersaing dengan label arah dan tujuan pendidikan, memberikan berbagai macam pilihan pada orang tua untuk menetapkan satu pilihanlembaga/sekolah. Salah satu lembaga/sekolah yang menjadi pilihan orang tua untuk membentuk perilaku anaknya adalah lembaga/sekolah yang bernafaskan islam, salah satunya adalah sekolah TK Aisyiyah 48 pulo Asem. TK Aisyiyah 48 merupakan salah satu lembaga yang bernafaskan Islam yang sudah membiasakan anaknya dalam berperilaku berdasarkan persfektif Islam.

\section{Metode Penelitian}

Penelitian ini menggunakan metode penelitian kualitatif. Metode penelitian kualitati menurut soegiono (2011:80) adalah metode penelitian naturalistic, penelitian yang dilakukan dalam kondisi alamiah (natural setting), atau disebut juga penelitian etnografi. Penelitian ini sebelumnya digunakan untuk penelitian antropobiologi budaya.

\section{Hasil Penelitian dan Diskusi}

Dalam konteks pendidikan formal, pendidikan dilaksanakan melalui proses pembelajaran yang pada dasarnya merupakan kegiatan sistematis berupa satu set peristiwa yang dilakukan oleh pengajar dalam rangka mengoptimalkan pencapaian tingkat kematangan dan situasi belajar. Sedangkan inti dari proses pembelajaran adalah "bagaimana agar siswa mau belajar, bukan hanya sekedar bagaimana guru mengajar". Sehubungan dengan hal tersebut, maka peranan pengajar yang terpenting adalah 
bagaimana cara menciptakan situasi dan kondisi yang paling efektif dan efisien agar terjadi proses belajar pada diri siswanya( Santoso, 2011:203). Proses belajar pada diri anak dipengaruhi berbagai factor baik dari dalam diri anak maupun dari lingkungan sekitar. Factor lingkungan sekitar yang pertama dikenal anak, adalah sekolah.Di sekolah anak akan belajar melalui apapun yang dicontohkan oleh gurunya. Guru sebagai individu yang menjadi panutan anak hendaknya dapat menjadi fasilitator, dan motivator, hal ini sesuai dengan filsafat pendidikandari bapak pendidikan Indonesia, Ki Hajar Dewantara,memyebutkan ada 3 falsafah yang harus di pegang oleh guru saat mengajar "Ing ngarso Sung Tulodho, Ing madyo mangun karso, Tut Wuri Handayani (Rahardjo, 2009:74).

Pertama Ing ngarso Sung Tulodho, artinyaseorang guru apabila didepan anakharus mampu memberi contoh atau menjadi panutan bagi peserta didiknya, yang kedua Ing madyo mangun karso, seorang guru apabila berada ditengah tengah anak harus mampu membangkitkan semangat atau memberi motivasi pada anak didik, yang ke tiga, Tut Wuri Handayani, seorang guru apabila berada dibelakang anak harus bisa mendorong anak agar senantiasa lebih maju.

Anak usia dini belajar dengan cara meniru yakni meniru dari lingkungan sekitarnya, hal ini sejalan dengan konsep belajar dari ki hajar dewantara. Konsep belajar anak usia dini ini masih berada pada konsep " Tri No", yaitu nonton, "niteni dan nirokke". Nonton (cognitive), nonton di sini adalah secara pasif dengan segenap panca indera. Niteni (affective) adalah menandai, mempelajari, mencermati apa yang ditangkap panca indera, dan nirokke (psychomotoric) yaitu menirukan yang positif untuk bekal menghadapi perkembangan anak (Dwiarso, 2010: 1).

Anak usia dini akan mencontoh dengan mencermati melalui panca indra dan menirukannya dalam bentuk perilaku. Perilaku anak dalam bertindak dan berbuat merupakan cerminan dari hasil belajar yang diperolehnya dari lingkungan.Lingkungan disini adalah sekolah. Sekolah TK Aisyiyah 48 para gurunya selalu memberikan pembiasaan pada anak untuk berprilaku dari sudut pandang persfektif islam.

Sebagai contoh saat anak melakukan kesalahan pada temannya, sehingga membuat temannya menangis. Guru tidak langsung menegur anak atau meminta anak meminta maaf melainkan guru memberikan kesempatan pada anak untuk mengutarakan pendapatnya tentang peristiwa yang sebenarnya terjadi, dengan begitu 
guru hanya mencoba memberikan contoh perilaku yang dicontohkan Rassullalah SAW dengan sepenggal cerita pendek yang intinya memberikan contoh meminta maaf sebelum orang lain meminta maaf karna Allah SWT sangat senang dengan umatnya yang saling maaf memaafkan dan Allah SWT maha memafkan dari segala kesalahan umatnya. Guru mengaitkan maha pemaaf Allah dengan sifat yang ada di Asmaul husna yang dibaca anak setiap pagi "Al-Afuw" yakni Allah maha pemaaf.Allah memiliki sifat maha pemaaf, kita makhluknya seharusnya mencontoh dari sifat yang dimiliki Allah dan Rasulnya.

Pengasuhan lainnya adalah saat guru menegur atau berbicara pada anak, guru selalu mencontohkan dengan suara lembut tidak berteriak dan diawali dengan kata “maaf".Sehingga anak saat berkomunikasi baik dengan guru maupun dengan temannya menggunakan suara lembut.

Selain anak diajarkan untuk berbicara dengan suara lembut anak diajarkan pula untuk saling berkasih sayang dengan sesamanya, sebagai contoh anak diajarkan untuk saling sayang menyayangi dengan temannya, main bersama dengan temannya, saling mengalah dengan temannya, memberikan kesempatan bermain bergantian dengan temannya, mau berbagi makanan mainan dengan temannya. Guru memberikan contoh dengan mengaitkan perilaku yang dicontohkan Rasullah SAW dengan saling sayang menyayangi.Allah juga memiliki sifat "Ar-rahman dan Ar-rahim.Maha pengasih dan maha penyayang.

Pengasuhan berikutnya adalah mengajarkan anak dengan keadilan, contoh perilaku yang dilakukan oleh guru adalah saat Guru memberikan kesempatan bermain, membagi makanan/ mainan, anak mengemukakan pendapat guru memberikan kesempatan yang sama pada setiap anak. Allah memiliki sifat "Al-adll”, Allah maha Adil.

Pengasuhan yang terakhir yakni pengasuhan dengan mengajarkan kejujuran, Guru memberikan contoh perilaku jujur yang di lakukan oleh Rasullah SAW, Rasullah selalu berkata jujur, dan berprilaku jujur yang memiliki julukan 'Assidiq" artinya dapat dipercaya/ jujur. Anak saat bermain dan mengambil barang anak diajarkan untuk berakhlak jujur dengan perilaku dan dengan ucapannya. 


\section{Simpulan}

Hasil penelitian menunjukan bahwa pengasuhan anak usia dini menurut persfektif ajaran islam di TK Aisyiyah 48 melalui pengasuhan Keteladanan / Contoh Rasullah SAW, kelembutan, kasih sayang, bersikap adil dan kejujuran.

\section{Daftar Pustaka}

Adil Fathi Abdullah. 2002. Pahami Anak Anda Anda Akan Sukses Mendidiknya. Alexandria: Dar al-Iman Alexandria. cetakan pertama.

Al-Jauziyah, Ibnu Qayyim.1999.Buah Ilmu. Jakarta: Pustaka Azzam.

Dwiarso Priyo. 2010. Napak Tilas Ajaran Ki Hadjar Dewantara, Yogyakarta: Majelis Luhur Pesatuan.

Elfindri. 2012. Pendidikan Karakter: Kerangka, Metode, Dan Aplikasi Untuk Pendidikan dan Professional. Jakarta: Baduose Media.

Ishlahunnisa. 2010. Mendidik Anak Perempuan Dari Buaian Hingga Pelaminan.Solo: Aqwam.

Naim Ngainun. 2012. Character Buliding Optimalisasi Peran Pendidikan dalam Pengembangan Ilmu\& Pembentukan Karakter bangsa. Jogjakarta : Ar-Ruzz Media.

Samani Muchlas Hariyanto. 2012. Pendidikan karakter. Bandung: PT Remaja Rosdakarya

Santoso Soegeng.2011. Konsep Pendidikan Anak Usia Dini menurut Pendirinya. Jakarta

Suparto Rahardjo.2009. "Ki Hajar Dewantara Biografi singkat". Jogjakarta : Garasi.

Tafsir Al Qur'an Al 'Azhim, Ibnu Katsir, terbitan Muassasah Qurthubah, cetakan pertama, $1421 \mathrm{H}$. 